Research Article

www.ijrap.net

\title{
KNOWLEDGE, ATTITUDES, AND PRACTICES TOWARDS HERBS AND HERBAL PRODUCTS AMONG HEALTH SCIENCES STUDENTS OF A UNIVERSITY IN UAE
}

Shahwan Moyad Jamal *, Khawaja Amal Hatem, Khasati Dana Samih

Ajman University, College of Pharmacy and Health Sciences, P.O. Box 346 Ajman UAE

Received on: 29/05/17 Accepted on: 20/06/17

\begin{abstract}
*Corresponding author
E-mail: moyad76@hotmail.com
\end{abstract}

DOI: $10.7897 / 2277-4343.083148$

\begin{abstract}
Herbal products and supplements are a branch of CAM, and are consumed for several health purposes, and mostly without a medical advice. To assess the knowledge, attitudes, and practices toward these herbals, we conducted a college-based survey, distributed to 334 students of dentistry and pharmacy in a university in United Arab Emirates. The survey included questions about the herbals used, purpose of consuming them, drug-herbals interaction, and safety of herbal consumed. Among the sample, only 5\% of students didn't use any herbals, at all. A high percentage of respondents believed that herbals are able to treat some medical conditions, while a weaker agreement was obtained regarding the safety of herbals. These results indicate that health sciences college students need to be counseled about the proper use of herbals.
\end{abstract}

Keywords: Herbs, Herbal products, safety.

\section{INTRODUCTION}

Complementary medicine is a vast term, a margin that encloses different practices and approaches to diagnose and treat. Herbal medicine is listed among 50 other complementary therapies, like acupuncture, homeopathy, and aromatherapy. These products are used widely for self-medications, and by some practitioners ${ }^{1}$.

The National Centre for Complementary and Integrative Health defines complementary medicine as "a non-mainstream practice used together with conventional medicine, and alternative medicine as "a non-mainstream practice used in place of conventional medicine" 2 .

Herbal medicines, a part of CAM, as defined by WHO are plantderived materials or products with therapeutic or other human health benefits which contain either raw or processed ingredients from one or more plants. and accordingly, a medicinal plant, as defined by WHO, is a plant which has been used for medical purposes at one time or another, and which, although not necessarily a product or available for marketing, is the original material of herbal medicines ${ }^{3}$.

Numerous studies discussed different herbals that could be used clinically, and the possible conditions that could be treated by herbalism, as herbs are variously used by society members for several targets, including healing illness and promoting health ${ }^{4}$.

Garlic for example, has been proved to be effective as antimicrobial (antibacterial, antiviral, antifungal, and antiparasitic), cardiovascular enhancer (antihypertensive, antiatherosclerotic, antithrombotic, hypolipidemic), anticancer, antiinflammatory, and immunomodulatory. But for some herbs that are added to food or drinks, a question rises regarding the knowledge of students about their efficacy ${ }^{5}$.

Questioning the safety, only little is known about the adverse effects of herbal medicines and their frequencies. Being natural products doesn't mean entirely safe, as misunderstood by majority. Herbs can be associated with serious side effects, as with Kava, which was reported to be associated with hepatotoxicity ${ }^{4}$.

The use of herbal medicines is spreading worldwide, despite their exclusion as drugs by the US Food and Drug Administration (US FDA). This questionnaire is designed to draw conclusions about the behavior and target of using herbs and herbal medicines by students of health sciences (Dentistry and Pharmacy) in a university in $\mathrm{UAE}^{6}$.

\section{MATERIALS AND METHODS}

A 14-questions survey was distributed to 400 health science students from dentistry and pharmacy, but total 334 were analyzed. This form is adapted from previous conducted forms ${ }^{7}$, ${ }^{8}$. Both paper and online surveys were prepared, and students were asked to respond on the spot.

Basic demographic data was obtained, including gender, age, year of study, college major, nationality, dietary habits, and parents' income. Survey was spread to students from all five years. The survey was also completed by both who use and don't use herbs or herbal supplements.

A question then included many of the well-known and much used herbs in the region, where they can choose and tick more than one herb or herbal product, if they already consume them. Students were also requested to mention if they use any other unlisted herb, or whether they did not use any.

They were then requested to reply to a question regarding the reason of consuming the herb or herbal product, with the following options: Maintain good health, ensure adequate nutrition and fill nutrition gap, treat minor illnesses, meet increased energy demands of the body, prophylaxis to prevent 
diseases, and all of the above. Students who did not use any left the question unanswered.

Last section was based on a 5-point likert-type scale, assessing the knowledge, attitudes, and practices of students toward the herbs and herbal products. Answers ranged from strongly disagree $^{1}$ to strongly agree ${ }^{5}$. Data was then analyzed using the Stata Data Analysis and Statistical Software.

\section{Ethical Statement}

Consent form was filled by the volunteering subjects in accordance with ICH GCP Guidelines. The identity was completely anonymous throughout the study and did not appear in any way in our research.

Table 1: Demographics of Consumers

\begin{tabular}{|c|c|c|}
\hline Demographic & Frequency & Percent \\
\hline \multicolumn{3}{|l|}{ Gender } \\
\hline Male & 109 & 32.63 \\
\hline Female & 225 & 67.37 \\
\hline \multicolumn{3}{|l|}{ Age } \\
\hline $17-21$ & 285 & 85.33 \\
\hline $22-25$ & 46 & 13.77 \\
\hline Above 25 & 3 & 0.9 \\
\hline \multicolumn{3}{|l|}{ Major } \\
\hline Pharmacy & 140 & 41.92 \\
\hline Dentistry & 194 & 58.08 \\
\hline \multicolumn{3}{|l|}{ Year } \\
\hline $1^{\text {st }}$ year & 177 & 52.99 \\
\hline $2^{\text {nd }}$ year & 66 & 19.76 \\
\hline $3^{\text {rd }}$ year & 40 & 11.98 \\
\hline $4^{\text {th }}$ year & 50 & 14.97 \\
\hline $5^{\text {th }}$ year & 1 & 0.3 \\
\hline \multicolumn{3}{|l|}{ Diet } \\
\hline Vegetarian & 27 & 8.08 \\
\hline Non-vegetarian & 307 & 91.92 \\
\hline \multicolumn{3}{|l|}{ Income } \\
\hline$<20,000$ & 140 & 41.92 \\
\hline$\geq 20,000$ & 194 & 58.08 \\
\hline \multicolumn{3}{|l|}{ Nationality } \\
\hline Arab & 311 & 93.11 \\
\hline Non-Arab & 23 & 6.89 \\
\hline
\end{tabular}

\section{RESULTS}

A total of 334 surveys were collected as both online and paper version, and analyzed. Table 1 shows the details of the demographic data analysis. $32.63 \%$ of the respondents were male students, where less than the half of them were pharmacy students (almost 42\%), leaving the rest from dentistry (around 58\%). A little past the half, approximately, were in first year of college (53\%), and almost $92 \%$ were on non-vegetarian diet. Among the respondents, nearly $93 \%$ were of Arabic origin.

In the 34-herbs containing table, mint lead the list, being the top most consumed herb by respondents in general, with a percentage of $81 \%$, followed by thyme (77\%), and cinnamon (69\%). Coming to herbals use and consumption, male were more prominent than females and wider consumers for most herbs, and dentistry students over pharmacy students. Figures $1,2, \& 3$.

A very large percent of the respondents $(40.36 \%)$ consumed the herb or herbal product for the all the five mentioned reasons, while the following top percentage $(17.51 \%)$ consumed them for only one purpose, which is to maintain good health.
Overall on the likert scale, majority of respondents supported that herbal products can be useful for treating certain medical conditions and/or promote health and wellness (mean=4.19). The least agreement was on consumers knowledge and awareness whether herbal products can have harmful side effects or not (mean=3.1), followed by a mean of 3.39 regarding whether herbal products can interact with other supplements or medications or not. Moderate acceptance was related to consumers' feeling of comfort in discussing the use of herbal products with the doctor or pharmacist (mean=3.67 and 3.56, respectively). Figure 4 .

\section{DISCUSSION}

Although this questionnaire was adapted from previously conducted ones, yet to our knowledge, it's the first leading survey that assesses the knowledge, attitudes, and practices of exclusively health care students in pharmacy and dentistry in a university in the UAE.

According to the statistical analysis of the data from the 2007 National Health Interview Survey, among U.S. adults over the past 12 months, almost 4 out of 10 adults used CAM, with nonvitamins, non-minerals, and natural products being the most commonly used $(17.7 \%)^{9}$.

Another study reveals that in one year, the prevalence of CAM use in U.K. was $41.1 \%$, with herbal medicine leading the list, being most popularly used, which demands responsibility from health care professionals to educate their patients ${ }^{10}$. Other studies based in the UAE demonstrated the high prevalence of herbal products, with the pharmacists' belief of their efficacy. These conclude that pharmacist should have wider knowledge about the indications, drug interactions, and adverse events and precautions of these products ${ }^{11}$. Another cross sectional study results showed that $76 \%$ of respondents used herbal products, with $38 \%$ of them were consuming one herb, at least ${ }^{12}$. Fortunately, our study's results were supportive to the previous ones.

Regarding the reason for using CAM, the most common identified target for approaching CAM is dissatisfaction with conventional medicine ${ }^{13}$. Other very common reasons are: the need to improve health and wellness, relieve illness-associated symptoms or medicine-associated side effects, or having a holistic health philosophy ${ }^{9}$. Our results show that consumers prefer a combination of some of these and other reasons. FDA's regulations for dietary supplements or ingredients are set in a different fashion than those for conventional drugs ${ }^{14}$, where there is no need for the manufacturer of a dietary supplement to provide the FDA with a proof to demonstrate the efficacy or safety of these before being marketed, ${ }^{15}, 16$ which raises the risk for increased prevalence of serious side effects that herbal remedies are associated with. Such side effects include increased risk of bleeding and adverse cardiac events. They are also able to potentially interact with other medications and decrease their efficacy, like St. John's wort speeding the breakdown of drugs like antidepressants and birth control pills ${ }^{17}$. Side effects of herbal preparations can also vary from hypersensitivity, as seen sometimes with soybeans, to hypertension and hypokalemia, as seen with liquorice ${ }^{18}$.

Being "natural" does not equal being "safe". Natural products can contain active molecules that may deteriorate humans' health ${ }^{19}$. This safety perception is further reinforced by the herbal supplements being purchased with no need for a prescription (OTC), availability in many locations, and being natural ${ }^{20}$. Adding to our cultural settings, being added to food frequently and served commonly supports the "safety" idea. 


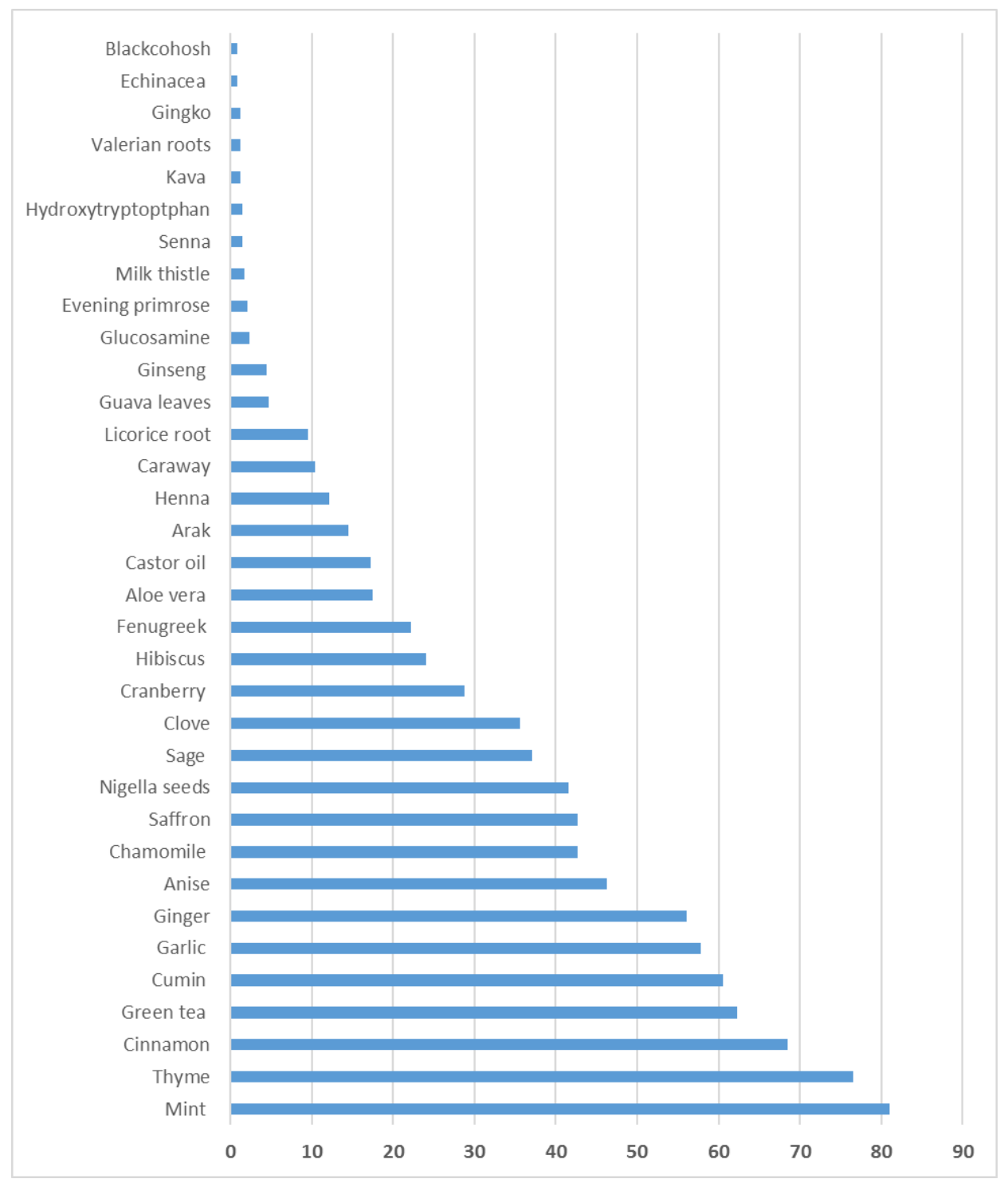

Figure 1: Percentage of Respondents Using Herbs

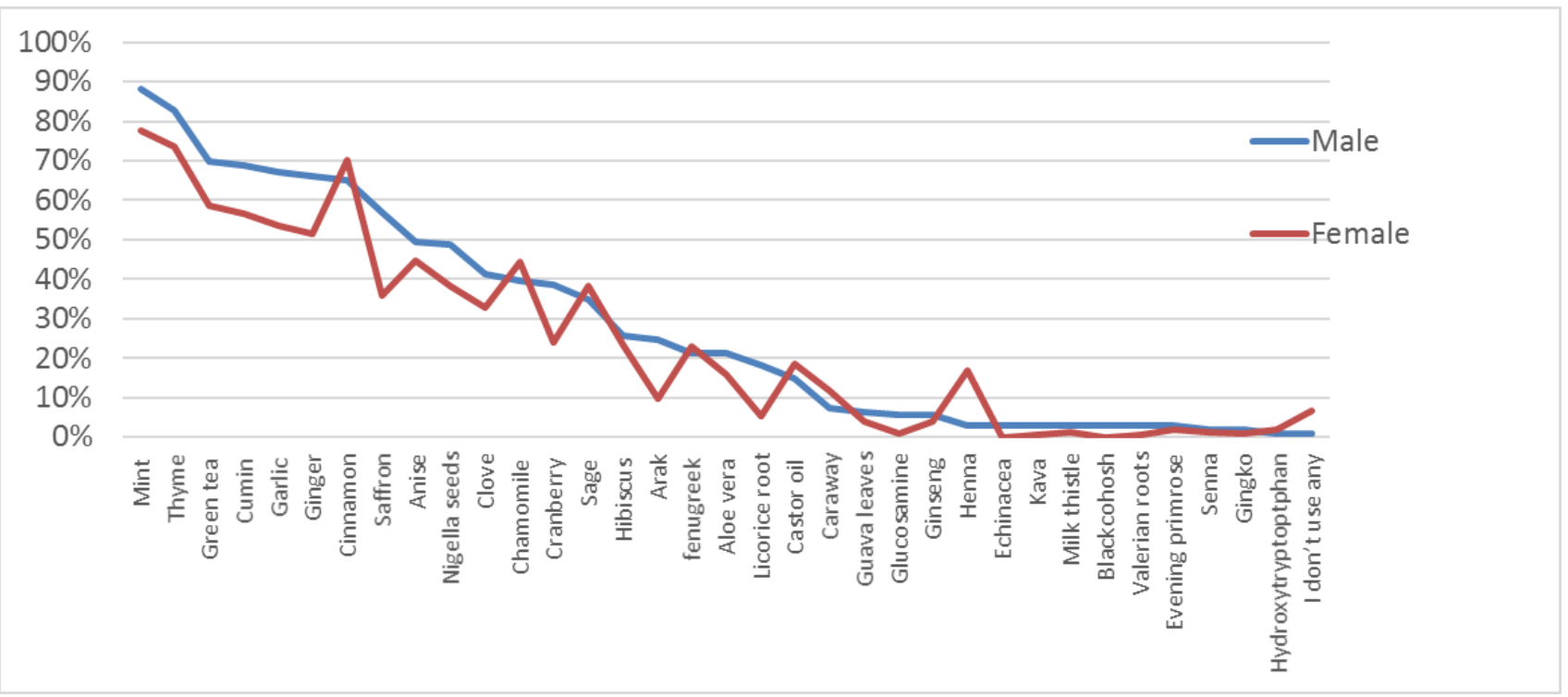

Figure 2: Percentages of Users By Gender 


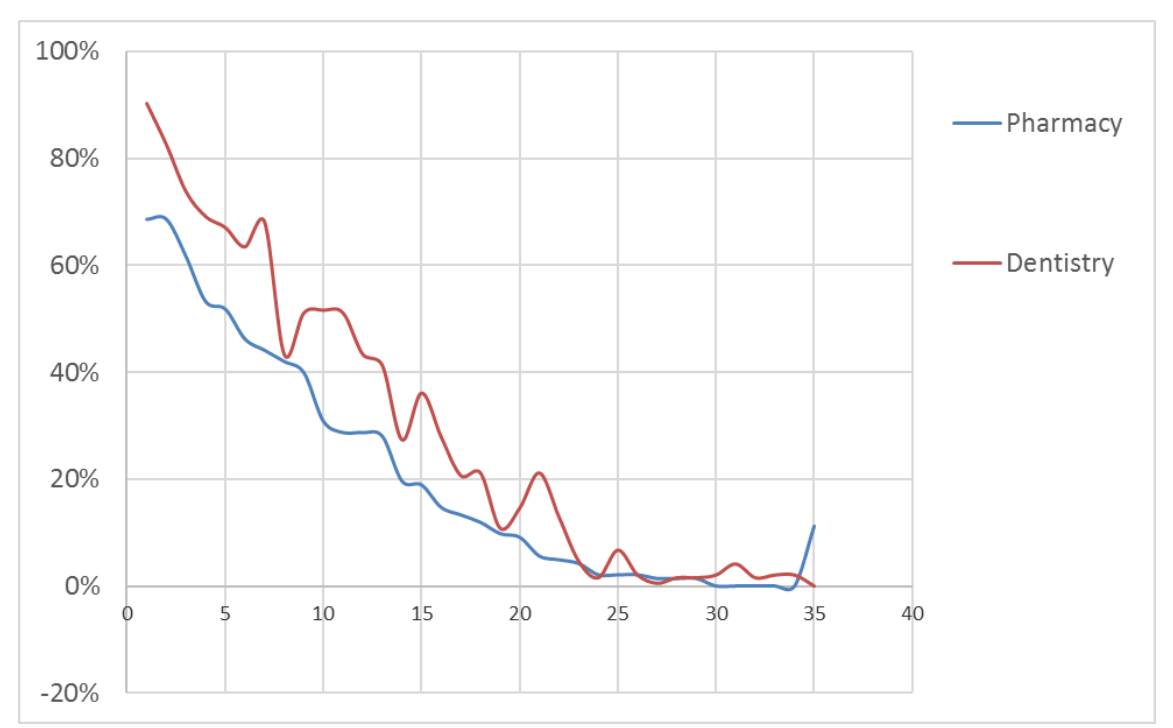

Figure 3: Percentages of Users By Major

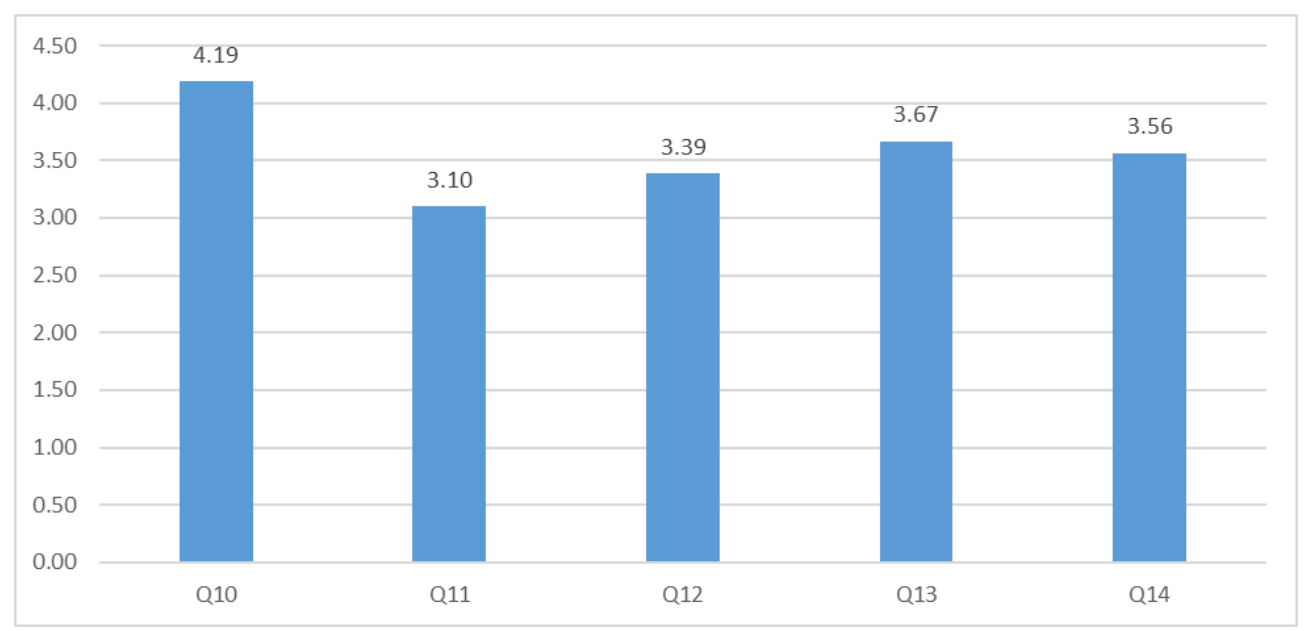

Figure 4: Likert-Scale Agreement Level Herbal

$5=$ Strongly Agree, $4=$ Agree, $3=$ Neutral, $2=$ Disagree, $1=$ Strongly Disagree

Q10: Herbal products can be useful for treating certain medical conditions and /or promote health and wellness.

Q11: Herbal products can have harmful side effects.

Q12: Herbal products can interact with other supplements or medications.

Q13: I feel comfortable discussing my use of herbal products with my doctor or health care provider.

Q14: I feel comfortable discussing my use of herbal products with my pharmacist.

Many of our respondents indicated a low knowledge regarding the safety of herbs and herbal medicines and their potential drug interactions. Many of the commonly consumed herbs, like St. John's wort, soy, garlic, ginseng, green tea, evening primrose, valerian, and aloe vera, are associated with major drug-herb interaction ${ }^{21}$. According to the results of our survey, green tea is consumed by $62 \%$ of respondents, followed by garlic, which is used by more than the half $(58 \%)$, then by Aloe vera $(18 \%)$. According to these proved studies, this raises the risk of drugherb interactions in students who consume an OTC or prescription-only medication, especially that green tea is served at most occasions, and garlic is widely added to food as a tasteenhancer.

As our survey's results indicate loss of comfort in informing the physician, health care provider, or pharmacist about the consumption of any herb, they are consistent with finding of other surveys conducted previously. This is due to various reasons, including the fear of disapproval of the herbal use, or the doctor did not ask. ${ }^{22,23}$ and as these CAM products are available in pharmacies, health-food stores, supermarkets, by mail orders, via the internet, and from other retail outlets. This supports selfmedication rather than medical consultation prior to their use ${ }^{1}$.

\section{LIMITATIONS}

This study has two limitations. First one is the sample size, which is relatively small and doesn't provide significant conclusion about practices in the region. Second one is the imbalance in the sample distribution, where more students and from $1^{\text {st }}$ year rather than other years. These might require more attention while coming to a conclusion, in order to yield a precise outcome.

\section{CONCLUSION}

Students were found to be consuming numerous herbal supplements, with less knowledge about their possible side effects and drug interactions. Students should be educated and 
aware about herbs and herbal products, and the ideal way to consume them with safety.

\section{REFERENCES}

1. Barnes J. Quality, efficacy and safety of complementary medicines: fashions, facts and the future. Part I: Regulation and quality. British Journal of Clinical Pharmacology 2003; 55(3): 226-233

2. NIH. Complementary, Alternative, or Integrative Health: What's In a Name? 2016. Available at: https://nccih.nih.gov/health/integrative-health\#cvsa. [Cited 2017 May 20]

3. WHO. Guidelines for the Appropriate use of Herbal Medicine, 1998. Available at: http://apps.who.int/medicinedocs/en/d/Jh2945e/4.html. [Cited 2017 May 24]

4. Barnes J. Quality, efficacy and safety of complementary medicines: fashions, facts and the future. Part II: Efficacy and Safety. British Journal of Clinical Pharmacology 2003; 55(4): 331-340

5. Mikaili P, Maadirad S, Moloudizargari M, Aghajanshakeri S, Sarahroodi S. Therapeutic Uses and Pharmacological Properties of Garlic, Shallot, and Their Biologically Active Compounds Article 2. Iranian Journal of Basic Medical Sciences 2013; 16(10): 1031-1048

6. Fahmy SA, Abdu S, Abuelkhair M. Pharmacists' attitude, perceptions and knowledge towards the use of herbal products in Abu Dhabi, United Arab Emirates. Pharm Pract 2010; 8(2): 109-115

7. Owen C, Toone T, Steed-Ivie M. A Survey of Dietary Supplement Knowledge, Attitudes, and Use in a Rural Population. Journal of Nutrition \& Food Sciences 2014; 4(5)

8. Alhomoud FK, Basil M, Bondarev A. Knowledge, Attitudes and Practices (KAP) Relating to Dietary Supplements Among Health Sciences and Non-Health Sciences Students in One of The Universities of United Arab Emirates. Journal of Clinical and Diagnostic Research 2016; 10(09): 04-09

9. Barnes PM, Bloom B, Nahin RL. Complementary and Alternative Medicine Use Among Adults and Children: United States, 2007. National Health Statistics Reports 2008; Number 12

10. Posadzki P, Watson LK, Alotaibi A, Emst E. Prevalence of use of complementary and alternative medicine (CAM) by patients/consumers in the UK: systematic review of surveys. Clinical Medicine RCPJ 2013; 13(2): 126-131

11. Fahmy SA, Abdu S, Abuelkhair M. Pharmacists' attitude, perceptions and knowledge towards the use of herbal products in Abu Dhabi, United Arab Emirates. Pharm Pract 2010; 8(2): 109-115

12. by United Arab Emirates citizens in Abu Dhabi Pharmacoepidemiology and Drug Safety 2008; 17(7): 725732
13. Jones J, Rayner S, Logue S, Imray E, Stewart D, Leslie SJ. National Health Service Healthcare Staff Experience and Practices Regarding Complementary and Alternative Medicine: An Online Survey. International Journal of Complementary \& Alternative Medicine 2017; 5(4)

14. FDA. Dietary Supplements, 2016. Available at: https://www.fda.gov/Food/DietarySupplements/default.htm. [Cited 2017 May 25]

15. Taniya T, Nardev S. A Review on Side Effects of Herbal Drugs. World Journal of Pharmacy and Pharmaceutical Sciences 2016; 5(6): 2150-2164

16. NIH. Using Dietary Supplements Wisely, 2014. Available at: https://nccih.nih.gov/health/supplements/wiseuse.htm. [Cited 2017 May 25]

17. NIH. Dietary Supplements: What You Need to Know, 2011. Available https://ods.od.nih.gov/HealthInformation/DS_WhatYouNee dToKnow.aspx. [Cited 2017 May 25]

18. Di Lorenzo C, Ceschi A, Kupferschmidt H, Lüde S, Nascimento EDS, Santos AD, Colombo F, Frigerio G, Nørby K, Plumb J, Finglas P, Restani P. Adverse effects of plant food supplements and botanical preparations: a systematic review with critical evaluation of causality. British Journal of Clinical Pharmacology 2015; 79(4): 578-592

19. Izzo AA, Hoon-Kim S, Radhakrishnan R, Williamson E. A Critical Approach to Evaluating Clinical Efficacy, Adverse Events and Drug Interactions of Herbal Remedies. Phytotherapy Research 2016; 30(5): 691-700

20. Snyder FJ, Dundas ML, Kirkpatrick C, Neill KS. Use and Safety Perceptions Regarding Herbal Supplements: A Study of Older Persons in Southeast Idaho. Journal of Nutrition For the Elderly 2009; 28(1): 81-95

21. Natural Medicine Comprehensive Database. Available at: http://naturaldatabase.therapeuticresearch.com/home.aspx?c $s=\& s=N D$. [Cited 2017 May 25]

22. Tangkiatkumjai M, Boardman H, Praditpornsilpa K, Walker DM. Prevalence of herbal and dietary supplement usage in Thai outpatients with chronic kidney disease: a crosssectional survey. BMC Complementary and Alternative Medicine 2013; 13(153)

23. Samojlik I, Mijatović V, Gavarić N, Krstin S, Božin B. Consumers' attitude towards the use and safety of herbal medicines and herbal dietary supplements in Serbia. International Journal of Clinical Pharmacy 2013; 35(5): $835-840$

\section{Cite this article as:}

Shahwan Moyad Jamal et al. Knowledge, attitudes, and practices towards herbs and herbal products among health sciences students of a university in UAE. Int. J. Res. Ayurveda Pharm. 2017;8(3):79-83 http://dx.doi.org/10.7897/2277-4343.083148

Source of support: Nil, Conflict of interest: None Declared

Disclaimer: IJRAP is solely owned by Moksha Publishing House - A non-profit publishing house, dedicated to publish quality research, while every effort has been taken to verify the accuracy of the content published in our Journal. IJRAP cannot accept any responsibility or liability for the site content and articles published. The views expressed in articles by our contributing authors are not necessarily those of IJRAP editor or editorial board members. 